\title{
Positioning Emerging Tourism Markets Using Tourism and Economic Indicators
}

\author{
Oscar Claveria* \\ AQR-IREA, University of Barcelona, 08034 Barcelona, Spain
}

\begin{abstract}
Most tourism research is centred in the world's top tourism destinations. The present study focuses on the interactions between tourism and economic variables in twenty emerging markets. First, we provide a descriptive analysis and we rank the countries according to their percentage average annual growth in relation to a set of economic and tourism indicators during the last decade. By means of categorical principal component analysis we synthesize all the information of the rankings into two components: growth in the contribution of tourism to economic activity, and growth in hotel accommodation. Finally, we project all twenty destinations in a twodimensional perceptual map. We obtain four clusters of destinations: Mali and Madagascar, with the top positions in terms of growth of the economic contribution of tourism; on the other extreme, Jamaica, Cyprus, Croatia, Portugal and Ireland, which are the more mature markets; Botswana, Bulgaria, and New Zealand, with the top positions regarding the growth in hotel accommodation; and in the opposite situation, the Republic of Moldova, which in spite of a moderate growth in hotel accommodation, has experienced a high increase in the contribution of tourism to economic activity. These results aim to shed light on the relative positioning of emerging destinations with respect to their potential competitors.
\end{abstract}

Keywords: Tourism destinations; Emerging markets; Positioning; Categorical Principal Components Analysis (CATPCA); Destination marketing

\footnotetext{
${ }^{*}$ Corresponding author. Tel.: +34-934021825; Fax.: +34-934021821. Department of Econometrics, Statistics and Applied Economics, University of Barcelona, Diagonal 690, 08034 Barcelona, Spain. Email: oclaveria@ub.edu
} 
Emerging destinations are playing an increasingly important role in the competitive tourism market. According to the UNWTO (2015), arrivals in emerging destinations between 2010 and 2030 are expected to increase at twice the rate of those in advanced economies, reaching a 57\% share of the market. Mature destinations in Northern and Western Europe and North America are expected to experience a comparatively slower growth during the next two decades. On the contrary, Africa, the Middle East, and especially Asia and the Pacific are the regions expected to grow faster. As a result, tourism in emerging markets is drawing increasing attention (Cohen et al., 2014). Despite the growing interest in emerging markets, most tourism research still focus on the world's top tourist destinations (UNWTO, 2015).

This study aims to shed some light on the evolution of tourism trends during the last decade in twenty emerging markets, understood as those with a low share in total inbound tourism which have experienced positive growth rates in terms of tourism receipts. Song et al. (2012) noted that one of the limitations of most tourism studies is the omission of economic indicators and the lack of attention paid to economic return. To cover this deficit, we combine official tourism data provided by the UNWTO with economic information at the macro level. We use the annual percentage growth rates of all variables to avoid the issues derived from working with non-stationary time series (Oh, 2005; Lim \& McAleer, 2002).

To that end, we apply a two-step procedure to position destinations (Claveria \& Poluzzi, 2016). This approach is based on nonlinear Principal Component Analysis (PCA), also known as Categorical Principal Component Analysis (CATPCA).

CATPCA can be regarded as a dimensionality reduction (DR) technique, and presents several advantages over standard PCA, as it can handle ordinal variables and deal with nonlinear relationships between variables.

In a first step, we rank the twenty destinations according to the average annual growth growth of the selected indicators between 2000 and 2010. In a second step, we synthesize all the information into two components, which we project on a twodimensional perceptual map (PM). The generated maps condense the dynamics in the international tourism market during the last decade by positioning each destination with respect to their competitors based on the scores in the two computed factors.

There have been very few attempts of implementing CATPCA in tourism research (Green, 2005; Correia et al., 2007; Claveria \& Poluzzi, 2016). This empirical study extends the coverage of previous research by assessing the utility of this technique in the positioning of emerging tourism markets. 
The remainder of the study is structured as follows. The next section provides a review of the literature. In Section 3 we describe the data and rank the selected twenty emerging markets regarding their average growth rate over the sample period. In Section 4, we cluster the destinations by means of CATPCA. Finally, Section 5 concludes.

\section{Literature Review}

Multivariate techniques for DR have been widely used in tourism studies. Some of the most applied DR procedures are PCA, cluster analysis, correspondence analysis (CA), and factor analysis (FA). See Hair et al. (2009), and Jolliffe (2002) for a detailed description of multivariate methods. DR techniques allow to generate lowerdimensional representations of data that preserve as much information as possible about the original dataset, therefore facilitating the detection of underlying structures in the relationships between variables (Chandra \& Menezes, 2001).

DR techniques have been used in image and perception analyses (Li, 2016; LlodràRiera et al., 2015; King et al., 2015; Zins, 2010; Phau et al., 2010), in motivation studies (Park \& Yoon, 2009; Ryan \& Glendon, 1998), and in other areas such as the design of tourism indicators (Fetscherin \& Stephano, 2016). Pike (2002, 2007) reviewed destination image papers published in the literature from 1973 to 2000, and from 2001 to 2007 respectively. Notwithstanding, one of the main areas in which DR techniques are widely implemented is in market segmentation studies (Guo et al., 2015; SinclariMaragh et al., 2015; Donaire et al, 2014; Rid et al., 2014; Dey \& Sarma, 2010; Park \& Yoon, 2009; Voges, 2007; Lee et al., 2006; Upchurch et al., 2004; Arimond \& Elfessi; 2001; Keng \& Cheng, 1999).

One of the most used DR techniques in the positioning of competitive destinations is Multidimensional Scaling (MDS). MDS is is a multivariate analytical procedure also known as Principal Coordinates Analysis (Torgerson, 1952). MDS allows to generate visual projections. These projections, also known as PMs, capture the level of similarity between individuals based on the proximity of individuals to each other. For an overview of MDS, see Borg \& Groenen (2005), and Fentom \& Pearce (1988). In a recent study, Marcussen (2014) reviewed the literature regarding the application of MDS to tourism research. The author found that the most common topics were image and positioning of destinations. 
An example of the former, is the work of Zins (2010), who depicted destination images of ten different countries from the perspective of two traveller segments via MDS analysis. Regarding destination positioning, there is a large number of studies addressing the relative status of one or several destinations by means of MDS (Kim et al., 2007; Omerzel, 2006; Kim \& Agrusa, 2005; Uysal et al., 2000; Andreu et al. 2000; Kim, 1998; Crompton et al., 1992; Gartner, 1989; Haahti, 1986).

More recently, Lozano \& Gutierrez (2011) applied MDS to analyse 25 European destinations. By means of MDS, the authors summarized the information of seven indicators into two dimensions (size of the tourism industry, and efficiency/weather), and found four clusters, of which one consisted of the most populated countries. Focusing on official data from Eurostat regarding monthly overnight stays from 1998 to 2009, Marcussen (2011) combined MDS with FA to position 33 European destinations, and found that European destinations could be grouped by major language spheres. Leung \& Baloglu (2013) analysed the competitiveness of sixteen Asia Pacific destinations regarding fourteen different factors. By means of three-dimensional PMs, the authors clustered the destinations in seven groups: Australia and New Zealand; Hong Kong and Singapore; China, India and Indonesia; Japan, Korea and Taiwan; Malaysia and Thailand; Mongolia, Philippines and Vietnam; and Cambodia, which was singled out. With respect to the three dimensions, the authors found that Hong Kong and Singapore were the most competitive destinations in the Asia Pacific region, followed by Japan, Korea, and Taiwan.

Marcussen (2014) applied MDS to illustrate how 24 different country destinations and four German regions tended to be chosen by overnight tourists originating from Germany for journeys of at least five nights in duration. Results significantly differed depending on whether tourists were from the north, the east, the west or the south of Germany. By combining MDS, MCA, and logistic regression, Li et al. (2015) analysed the position of the United States (US) against its major non-Asian competitors.

In order to deal with nonlinear relationships in data and with qualitative information, the PCA framework has been progressively extended. CATPCA can be regarded as a development of PCA (Meulman et al., 2004). CATPCA presents several advantages over standard PCA: it allows incorporating nominal and ordinal variables, and it does not assume that the relationships between variables are linear. As a result, CATPCA can uncover nonlinear patterns between variables. An additional advantage of CATPCA is that, due to the nonlinear transformations of the nominal and ordinal variables achieved by optimal quantification, it tends to concentrate more variation in the first few principal components (De Leeuw \& Meulman, 1986). 
CATPCA is also known as nonlinear PCA. Linting et al. (2007) provided a detailed overview on how to implement nonlinear PCA. As opposed to MDS, there are very few studies that apply CATPCA for tourist data. Green (2005) combined CATPCA with MDS to identify different groups regarding the perception of the effects of tourism development in a small community in Thailand. Correia et al. (2007) used CATPCA to analyse Portuguese outbound tourism demand, and found six factors influencing the formation of the perceptions and the choice of exotic destinations of Portuguese tourists.

In this study we use CATPCA to position and cluster twenty emerging markets. We generate two-dimensional projections based on the rankings of the destinations with respect to their average annual growth in a set of official indicators that combine tourism and economic information. While the connection between tourism and economic growth has been analysed using different econometric techniques (PabloRomero \& Molina, 2013), it has hardly been addressed by means of DR techniques. Hence, this study aims to highlight the utility of CATPCA for destination marketing and management using available official macro data, and to assess its performance in the positioning of twenty emerging destinations with respect to their competitors.

\section{Data and Methods}

The study focuses on emerging markets. The term was first coined in the 80 s by the economists at the World Bank to refer to emerging economies. Nevertheless, the main idea is not constrained to economic weight, but rather to the transitory nature of the phenomenon. As there is not a unique definition of emerging market (Mody, 2004), the selection criteria applied in this study are that markets experienced a positive average annual growth rate in terms of tourism receipts during the sample period (2000-2010), and that they lied above the $70^{\text {th }}$ percentile in total inbound tourism in 2010 (Table 1). A final constraint is that the five regions defined by the UNWTO were represented in the selection of destinations.

As a result, the study focuses on twenty destinations distributed within the five major regions: five destinations from sub-Saharan Africa (Botswana, Madagascar, Mali, Mauritius, and South Africa); four destinations from southern Europe (Croatia, Cyprus, Portugal, and Slovenia), four form Eastern Europe (Bulgaria, Latvia, Lithuania, and Moldova), and one from northern Europe (Ireland); one form central America (Belize), one form the Caribbean (Jamaica), and one from South America (Paraguay); one form south Asia (Sri Lanka), and one from Oceania (New Zealand); and one form the Middle East (Jordan). 
Table 1

Frequency distribution of inbound tourism 2010

First, we have constructed a dataset comprised of three major sources of official information: tourism data from the Compendium of Tourism Statistics provided by the UNWTO (http://www2.unwto.org/content/data-0), economic data from the World Bank (http://data.worldbank.org/indicator/NY.GDP.MKTP.KD.ZG), and the Human Development Index (HDI) provided by the UN (http://hdr.undp.org/en/content/humandevelopment-index-hdi). The HDI is a composite indicator of life expectancy, education, and income per capita (Alzate, 2006), whose introduction allows us to incorporate the interactions between tourism and development beyond a strictly economic sense. Tourism indicators include: overnight visitors (thousands), total expenditure (US\$ millions), occupancy rate (\%), rooms, and inbound expenditure over GDP (\%). We combine the first two indicators to calculate the ratio of total expenditure per tourist. Economic information includes the Gross Domestic Product (GDP) at market prices based on constant local currency. Table 2 presents a summary of the descriptive analysis of all the variables expressed in annual percentage growth rates.

\section{Table 2}

Summary of descriptive analysis by indicators (2000-2010)

We complement the descriptive analysis with a graphical analysis of the evolution of the main variables (Fig. 1).

Fig. 1. Overnight visitors, expenditure and GDP in each country vs. International inbound tourists

Although the evolution of total expenditure shows positive co-movements with respect to the evolution of the number of overnight visitors during most of the sample period in most destinations, there are notable differences in the evolution of both variables across countries, which are very heterogeneous. From destinations like Belize and Botswana which are heavily dependent on tourism (Ramsey \& Everitt, 2008; Lenao \& Basupi, 2016), to others such as Ireland or Sri Lanka, where tourism is not one of the main contributors to GDP (OECD, 2010; Buultjens et al., 2005). See Peypoch et al. (2012), Durbarry (2004), Matei (2015), Dwyer et al. (2012), and Schiff \& Becken (2011) for recent tourism research about Madagascar, Mauritius, Slovenia and New Zealand respectively. 
Table 3

Ranking of destinations

Finally, we have ranked in decreasing order the twenty destinations according to the average annual growth experienced over the period comprised from 2000 to 2010 for each variable (Table 3). The rankings in seem to discriminate between emerging and more mature destinations: while Madagascar and Mali are in the top positions for most indicators, Cyprus and Portugal tend to get the lowest positions regarding the average growth during the decade.

\section{Results}

In this section we synthesise the information of the rankings into two indicators. We then map the different destinations in two-dimensional scatterplots. We implement a CATPCA to reduce the dimensionality of data, and complement the results of the analysis with a PM to cluster the destinations. CATPCA transforms the original set of correlated variables into a smaller set of uncorrelated variables (Linting et al., 2007). First, in order to deal with nominal and ordinal variables, CATPCA begins by applying an optimal quantification procedure, the result of which can be seen in the transformation plots (Fig. 2), which display the nonlinear function that relates the category quantifications versus the original categories.

Fig. 2. Transformation plots

Once the variables are transformed, we generate a screeplot with the eigenvalues of the correlation matrix of the quantified variables to determine the number of required dimensions (Fig. 3). The elbow indicating a noticeable difference in slopes reveals the last component that accounts for a considerable amount of variance. We can see that the data could be projected onto two or three dimensions. As shown in the Fig. 3, there is little gain in incorporating a third dimension, so we opt for a two-dimensional projection, which facilitates the interpretation of the results. The first two dimensions account for $67 \%$ of total variance (Table 4 ).

Fig. 3. Screeplot

Table 4

CATPCA - Summary

Table 5

Loadings 
In a third step, we use the component loadings in Table 5 to label the two reduced dimensions. We have included two additional variables: the ranking regarding the world position in terms of inbound tourism in 2010, and the region, which is a nominal variable indicating the UNWTO region the destination belongs to. The variables that obtain high loadings in the first dimension are the rankings regarding expenditure per tourist, total expenditure, inbound expenditure per GDP, HDI, and world position. As a result, the first dimension better captures the aspects reflecting the growth in the contribution of tourism to economic activity and human development. In the second dimension, there are three variables with high loadings: overnight visitors, rooms and occupancy rates. Thus, we label the first dimension as "growth in the contribution of tourism to economic activity", and the second as "growth in hotel accommodation (supply and demand)".

The loadings of each variable on the two components are used as the coordinates of the end point of each vector in the biplot of the two dimensions obtained with CATPCA (Fig. 4). Each country is represented with a number: Belize (1), Botswana (2), Bulgaria (3), Croatia (4), Cyprus (5), Ireland (6), Jamaica (7), Jordan (8), Latvia (9), Lithuania (10), Madagascar (11), Mali (12), Mauritius (13), Moldova (14), New Zealand (15), Paraguay (16), Portugal (17), Slovenia (18), South Africa (19), and Sri Lanka (20).

In order to interpret the results, two key elements have to be taken into account: the longitude of the vectors (the longer, the better fit), and the direction of the vectors. Similar directions in the same sense, are indicative of a positive relation; similar directions in opposite senses (making approximately a $180^{\circ}$ angle with each other) are related to variables that negatively related; finally, vectors making a $90^{\circ}$ angle correspond to variables that are not related.

We can group the variables in Fig. 4 into five groups. First, the rankings regarding occupancy, overnight visitors, rooms, and GDP, which tend to coalesce together, indicating a close and positive relation between the variables. Second, inbound expenditure over GDP, total expenditure, and HDI, which also tend to merge. The $180^{\circ}$ angle between each group, suggests that there is a negative relation between both. The vectors of the expenditure per tourist, region and world position take different directions. Thus, higher positions regarding the number of tourists are not very correlated with the second group of variables, and negatively correlated with the first group of variables. We also find that the position regarding the average growth in the expenditure per tourist has no relation to the region, and a negative one with the first group of variables, which includes overninght visitors, rooms and GDP. 
Fig. 4. Biplot

Fig. 5. Perceptual map

Finally, we generate a scatterplot to project the first two dimensions obtained by means of CATPCA (Fig. 5). The interpretation of the results is conditioned by the way in which destinations are ranked. Given that countries were ranked according to their average annual growth in decreasing order, countries in the top positions of the rankings (highest growth rates) tend to obtain the lowest scores in the dimension where that variable has a high loading, and vice versa. The only exception are the two variables that are ranking items which were not expressed as growth rates: the region and the world position. In this case, destinations in high positions tend to score high in the first dimension, hence the negative sign in the loading.

The PM is divided in four quadrants. A visual inspection allows to cluster the destinations into several groups that stand out. In the lower left quadrant, Mali and Madagascar are the destinations with the two lowest scores in the first dimension. South Africa and Belize are close together near the centre of coordinates, with intermediate scores in both dimensions. Mauritius and Jordan are very close to each other. Botswana is the destination with the lowest score in the second dimension, and it is positioned close to Bulgaria and New Zealand. In the top right quadrant, Cyprus and Jamaica are closely grouped, obtaining the two highest scores in the first dimension, and high ones in the second. In this same quadrant, we find Portugal and Ireland, with the highest scores in the second dimension and high ones in the first. In the first top left quadrant, the Republic of Moldova is grouped apart, obtaining a high score in the second dimension, but the third lowest in the first.

The positioning of Mali and Madagascar is indicative of a high average growth both in terms of the contribution of tourism to economic activity and of hotel accommodation. In the opposite extreme, we have Portugal and Ireland, and Cyprus and Jamaica, with high scores in both dimensions, indicating lower average growth rates than the rest of the destinations, which is associated with a higher level of maturity. Croatia is the closest destination to this group. The Republic of Moldova is positioned apart from the rest of destinations, and the combination of a high score in the second dimension together with a lower one in the first, indicates that in spite of a moderate growth in terms of hotel supply and demand, the contribution of tourism to economic activity has increased during the last decade in comparison to the rest of the destinations. 
Some of these results are in line with those presented in two recent studies. Assaf \& Tsionas (2015) ranked 101 countries according to 20 indicators grouped in three dimensions: infrastructure, human resources and nature. Regarding overall quality in the short run, the authors evaluated sixteen of the twenty destinations analysed in this study, and ranked them in the following order: New Zealand, Ireland, Mauritius, Portugal, Sri Lanka, Slovenia, Cyprus, Lithuania, Croatia, Latvia, Jordan, Jamaica, Bulgaria, Madagascar, Moldova and Paraguay.

In another study, Assaf et al. (2015) found that transport infrastructure, welcomeness, and crime rate are the most influential factors for the location of international hotels. Of the twenty destinations analysed in this study, New Zealand is in the top twenty best positions of the three rankings. Portugal, Ireland and Mauritius are also within the twenty top positions in terms of welcomeness, and Ireland is next to New Zealand regarding safety. On the other side, Paraguay figures in the top ten worst destinations with respect to infrastructure, welcomeness and crime.

In spite of some common results regarding the rankings of destinations, in this study we have exclusively used official macro data, and we have ranked the destinations according to their average annual growth rates which capture the evolution of the indicators during the sample period.

\section{Conclusions and Recommendations}

Destination positioning is critical in the changing tourism market. This study aims to provide managers with a methodology to position destinations with respect to their competitors using official indicators. With this aim, first we undertook a descriptive and graphical analysis of the main trends in twenty emerging destinations, focusing on the interactions between tourism and economic information over the period comprised between 2000 and 2010. Then, destinations were ranked according to the average annual growth experienced over the sample period in overnight visitors, total expenditure, inbound expenditure over GDP, expenditure per tourist, rooms, occupancy, GDP and HDI. By means of a categorical principal component analysis, we summarized all the information into two components: growth in the contribution of tourism to economic activity, and in hotel accommodation both in terms of supply and demand.

We used a biplot to analyse the relation between the different indicators. We found that higher positions regarding the number of tourists are not correlated with the position regarding average growth in expenditure over GDP, total expenditure, and 
HDI, but they are negatively correlated with the position in terms of average growth of overninght visitors, rooms and GDP. We also found that the position regarding the average growth in the expenditure per tourist has no relation to the region, and a negative one with the position regarding average growth of overninght visitors, rooms and GDP.

Finally, we positioned the twenty destinations, and found that Mali and Madagascar occupied top positions regarding both the growth in the contribution of tourism to economic activity and in hotel accommodation, indicating the potential of both destinations. On the other end, Jamaica, Cyprus, Croatia, Portugal, and Ireland to a lesser extent, which are more mature destinations, presented the latter positions. Bulgaria, Botswana, and New Zealand obtain leading positions with respect to the growth in hotel accommodation. Grouped apart from the other three groups, the the positioning of the Republic of Moldova shows that the contribution of tourism to economic activity has increased during the last decade in comparison to the rest of the destinations. We hope that these results contribute towards the improvement of marketing strategies in emerging destinations.

This is a descriptive study, and inference cannot be drawn from the results. Nevertheless, the proposed methodology can be easily implemented in destination positioning studies. Due to the lack of available information, we have not included additional tourism indicators such as the contribution of tourism to employment, which could give further insight into the contribution of tourism development to economic growth. Another question left for future research is the comparison of the results with those obtained with other new dimensionality reduction techniques such as selforganizing maps.

\section{Acknowledgements}

We would like to thank the Editor and two anonymous referees for their useful comments and suggestions. We also wish to thank Laura Muñoz and Jacinta García at the World Tourism Organization (UNWTO) for providing us with the data used in this study.

\section{References}

Alzate, M. M. (2006). Welfare recipients' quality of life: lessons from the United Nations' Human Development Index for the US welfare policy. European Journal of Social Work, 9(1), 85-101. 
Andreu, L., Bigné, J. E., \& Cooper, C. (2000). Projected and perceived image of Spain as a tourist destination for British travellers. Journal of Travel and Tourism Marketing, 9(4), 47-67.

Arimond, G., \& Elfessi, A. (2001). A clustering method for categorical data in tourism market segmentation research. Journal of Travel Research, 39(4), 391-397.

Assaf, A. G., \& Tsionas, E. G. (2015). Incorporating destination quality into the measurement of tourism performance: A Bayesian approach. Tourism Management, 49, 58-71.

Assaf, A. G., Josiassen, A., \& Agbola, F. W. (2015). Attracting international hotels: Locational factors that matter most. Tourism Management, 47(1), 329-340.

Borg, I., \& Groenen, P. J. F. (2005). Modern multidimensional scaling: Theory and applications (2nd Ed.). New York: Springer-Verlag.

Buultjens, J., Ratnayake, I., Gnanapala, A., \& Aslam, M. (2016). Tourism and its implications for management in Ruhuna National Park (Yala), Sri Lanka. Tourism Management, 26(5), 733-742.

Chandra, S., \& Menezes, D. (2001). Applications of multivariate analysis in international tourism research: The marketing strategy perspective of NTOs. Journal of Economic and Social Research, 3(1), 77-98.

Claveria, O., \& Poluzzi, A. (2016). Positioning and clustering of the world's top tourist destinations by means of dimensionality reduction techniques for categorical data. Journal of Destination Marketing \& Management. In Press.

Cohen, S. A., Prayag, G., \& Moital, M. (2014). Consumer behaviour in tourism: Concepts, influences and opportunities. Current Issues in Tourism, 17(10), 872-909.

Correia, A., Oom do Valle, P., \& Moço, C. (2007). Modeling motivations and perceptions of Portuguese tourists. Journal of Business Research, 60(1), 76-80.

De Leeuw, J., \& Meulman, J. J. (1986). Principal component analysis and restricted multidimensional scaling. In W. Gaul and M. Schader (Eds.) Classification as a Tool of Research. Amsterdam: North-Holland.

Dey, B., \& Sarma, M. K. (2010). Information source usage among motive-based segments of travellers to newly emerging tourist destinations. Tourism Management, 31(3), 341-344.

Donaire, J. A., Camprubí, R., \& Galí, N. (2014). Tourist clusters from Flickr travel photography. Tourism Management Perspectives, 11, 26-33.

Durbarry, R. (2004). Tourism and economic growth: the case of Mauritius. Tourism Economics, 10(4), 389-401.

Dwyer, L., Cvelbar, L. K., Edwards, D., \& Mihalic, T. (2012). Fashioning a destination tourism future: The case of Slovenia. Tourism Management, 33(2), 305-316.

Fentom, M., \& Pearce, P. (1988). Multidimensional scaling and tourism research. Annals of Tourism Research, 15, 236-254.

Fetscherin, M., \& Stephano, R-M. (2016). The medical tourism index: Scale development and validation. Tourism Management, 52(1), 539-556.

Gartner, W. C. (1989). Tourism image: Attribute measurement of state tourism products using multidimensional scaling techniques. Journal of Travel Research, 28, 16-20.

Green, R. (2005). Community perceptions of environmental and social change and tourism development on the island of Koh Samui, Thailand. Journal of Environmental Psychology, 25(1), 37-56.

Guo, Y., Guillet, B. D., Kucukusta, D., \& Law, R. (2015). Segmenting hotel customers based on rate fences using conjoint and cluster analyses. Journal of Travel \& Tourism Marketing, 21(2), 118-136.

Haahti, A. J. (1986). Finland' s competitive position as a destination. Annals of Tourism Research, 13(1), 11-35.

Hair, J. F., Black, W. C., Babin, B. J., \& Anderson, R. E. (2009). Multivariate data analysis (7th Ed.). Upper Saddle River, NJ: Prentice Hall. 
Jolliffe, I. T. (2002). Principal component analysis (2nd Ed.). Springer Series in Statistics.

Keng, K. A., \& Cheng, J. L. (1999). Determining tourist role typologies: An exploratory study of Singapore vacationers. Journal of Travel Research, 37 (4): 382-390.

Kim, D. J., Kim, W. G., \& Han, J. S. (2007). A perceptual mapping of online travel agencies and preference attributes. Tourism Management, 28(2), 591-603.

Kim, H. (1998). Perceived attractiveness of Korean destinations. Annals of Tourism Research, 25(2), 340-361.

Kim, S. S., \& Agrusa, J. (2005). The positioning of overseas honeymoon destinations. Annals of Tourism Research, 32(4), 887-904.

King, C., Chen, N., \& Funk, D. C. (2015). Exploring destination image decay. Journal of Hospitality and Tourism Research, 39(1), 3-31.

Lee, C. K., Lee, Y. K., Bernhard, B. J., \& Yoon, Y. S. (2006). Segmenting casino gamblers by motivation: A cluster analysis of Korean gamblers. Tourism Management, 27(5), 856-866.

Lenao, M., \& Basupi, B. (1988). Ecotourism development and female empowerment in Botswana: A review. Tourism Management Perspectives, 18, 51-58.

Leung, X. Y., \& Baloglu, S. (2013). Tourism competitiveness of Asia Pacific destinations. Tourism Analysis, 18(4), 371-384.

Li, X. R. (2016). Emerging market research: New bottles AND new wine?. Journal of Travel Research, 55(4), 419-426.

Li, X. R., Cheng, C. K., Kim, H. \& Li, X. (2015). Positioning USA in the Chinese outbound travel market. Journal of Hospitality and Tourism Research, 39(1), 75104.

Lim, C., \& McAleer, M. (2002). Time series forecasts of international travel demand for Australia. Tourism Management, 23(4), 389-396.

Linting, M., Meulman, J. J., Groenen, P. J. F., \& Van der Kooij, A. J. (2007). Nonlinear principal component analysis: Introduction and application. Psychological Methods, 12(3), 336-358.

Llodrà-Riera, I., Martínez-Ruiz, M. P., Jiménez-Zarco, A. I, \& Izquierdo-Yusta, A. (2015). A multidimensional analysis of the information sources construct and its relevance for destination image formation. Tourism Management, 48(1), 319-328.

Lozano, S., \& Gutiérrez, E. (2011). Efficiency analysis of EU-25 member states as tourist destinations. International Journal of Services Technology and Management, 15(1/2), 69-88.

Marcussen, C. H. (2011). Visualising groups of European destinations. European Journal of Travel Research, 4(2), 180-190.

Marcussen, C. H. (2014). Multidimensional scaling in tourism literature. Tourism Management Perspectives, 12, 31-40.

Meulman, J. J., Heiser, W. J., \& SPSS. (2004). SPSS Categories 13.0. Chicago, Illinois: SPSS Inc.

Mody, A. (2004). What is an emerging market? IMF Working Paper, WP-04-177.

OECD (2010). OECD Tourism trends and policies 2010. OECD Publishing.

Oh, C. O. (2005). The contribution of tourism development to economic growth in the Korean economy. Tourism Management, 26(1), 39-44.

Omerzel, D. G. (2006). Competitiveness of Slovenia as a Tourist Destination. Managing Global Transitions, 4(2), 167-189.

Pablo-Romero, M. D. P., \& Molina, J. A. (2013). Tourism and economic growth: A review of empirical literature. Tourism Management Perspectives, 8, 28-41.

Park, D. B., \& Yoon, Y. S. (2009). Segmentation by motivation in rural tourism: A Korean case study. Tourism Management, 30(1), 99-108.

Peypoch, N., Randriamboarison, R., Rasoamananjara, F., \& Solonandrasan, B. (2012). The length of stay of tourists in Madagascar. Tourism Management, 33(5), 12301235. 
Pike, S. (2002). Destination image analysis - A review of 142 papers from 1973 to 2000. Tourism Management, 23(5), 541-549.

Pike, S. (2007). Destination image literature 2001 to 2007. Acta Turistica, 19(2), 107125.

Ramsey, D., \& Everitt, J. (1988). If you dig it, they will come!: Archaeology heritage sites and tourism development in Belize, Central America. Tourism Management, 29(5), 909-916.

Rid, W., Ezeuduji, I. O., \& Pröbstl-Haider, U. (2014). Segmentation by motivation for rural tourism activities in The Gambia. Tourism Management, 40, 102-116.

Ryan, C., \& Glendon, I. (1988). Application of leisure motivation scale to tourism. Annals of Tourism Research, 25(1), 169-184.

Schiff, A., \& Becken, S. (2011). Demand elasticity estimates for New Zealand tourism. Tourism Management, 32(3), 564-575.

Sinclari-Maragh, G., Gursoy, D., \& Vieregge, M. (2015). Residents' perceptions toward tourism development: A factor-cluster approach. Journal of Destination Marketing \& Management, 4(1), 36-45.

Singh, A., Dev, C. S., \& Mandelbaum, R. (2014). A flow-through analysis of the US lodging industry during the great recession. International Journal of Contemporary Hospitality Management, 26(2), 205-224.

Torgerson, W. S. (1952). Multidimensional scaling: I. Theory and method. Psychometrika, 17(4), 401-419.

UNWTO (2015). UNWTO Tourism highlights, 2015 Edition. UNWTO.

Upchurch, R. S, Ellis, T., \& Seo, J. (2004). Applying the hierarchical cluster analysis procedure upon the process of yield management-A comparative study. Journal of Travel \& Tourism Marketing, 16(4), 47-58.

Uysal, M., Chen, J., \& Williams, D. R. (2000). Increasing state market share through a regional positioning. Tourism Management, 21(1), 89-96.

Voges, K. E. (2007). Rough clustering of destination image data using an evolutionary algorithm. Journal of Travel \& Tourism Marketing, 21(4), 121-137.

Zins, A. H. (2010). Mapping beneficial destination images. Journal of Hospitality and Tourism Management, 17, 96-107. 
Table 1

Frequency distribution of inbound tourism 2010

\begin{tabular}{lccclccc}
\hline Country & $n(i)$ & $f(i)$ & $\begin{array}{c}\text { World } \\
\text { position }\end{array}$ & Country & $n(i)$ & $f(i)$ & $\begin{array}{c}\text { World } \\
\text { position }\end{array}$ \\
\hline Croatia & 9,111 & $1.049 \%$ & 25 & Slovenia & 1,869 & $0.215 \%$ & 64 \\
South Africa & 8,074 & $0.930 \%$ & 30 & Lithuania & 1,507 & $0.174 \%$ & 70 \\
Ireland & 7,134 & $0.821 \%$ & 32 & Latvia & 1,373 & $0.158 \%$ & 73 \\
Portugal & 6,756 & $0.778 \%$ & 35 & Mauritius & 935 & $0.108 \%$ & 89 \\
Bulgaria & 6,047 & $0.696 \%$ & 36 & Sri Lanka & 654 & $0.075 \%$ & 103 \\
Jordan & 4,207 & $0.484 \%$ & 43 & Paraguay & 465 & $0.054 \%$ & 115 \\
New Zealand & 2,435 & $0.280 \%$ & 54 & Belize & 242 & $0.028 \%$ & 135 \\
Cyprus & 2,173 & $0.250 \%$ & 59 & Madagascar & 196 & $0.023 \%$ & 143 \\
Botswana & 2,145 & $0.247 \%$ & 61 & Mali & 169 & $0.019 \%$ & 146 \\
Jamaica & 1,922 & $0.221 \%$ & 63 & Moldova & 7.6 & $0.001 \%$ & 174 \\
\hline
\end{tabular}

Note: Overnight visitors are measured in thousands. World position out of 177 destinations.

Table 2

Summary of descriptive analysis by indicators (2000-2010)

\begin{tabular}{lcccc}
\hline Variable & Mean & Minimum & Maximum & $\begin{array}{c}\text { Standard } \\
\text { Deviation }\end{array}$ \\
\hline Overnight visitors & 5.09 & -63.53 & 124.19 & 12.28 \\
Total expenditure & 11.16 & -89.29 & 100.84 & 17.82 \\
Inbound expenditure / GDP & 1.32 & -85.63 & 151.93 & 14.73 \\
Rooms & 5.32 & -8.82 & 182.25 & 7.27 \\
Occupancy rates & 1.25 & -66.67 & 81.82 & 11.49 \\
Expenditure per tourist & 7.75 & -91.15 & 155.90 & 19.36 \\
GDP & 3.50 & -14.81 & 13.09 & 3.63 \\
\hline
\end{tabular}

Note: Statistics are conducted for the twenty destinations. 
Fig. 1. Overnight visitors, expenditure and GDP in each country vs. International inbound tourists

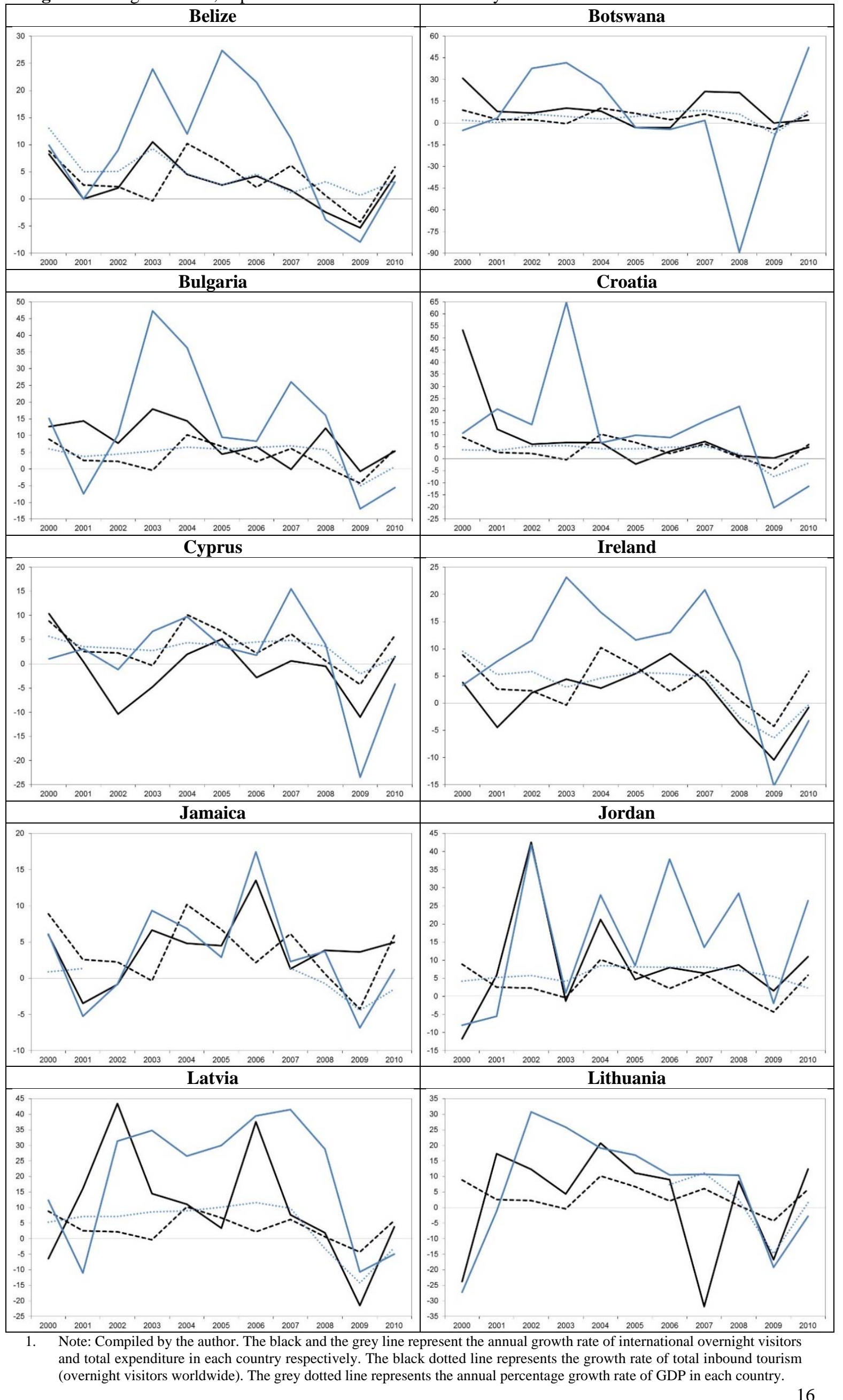


Fig. 1 (cont.). Overnight visitors, expenditure and GDP in each country vs. International inbound tourists

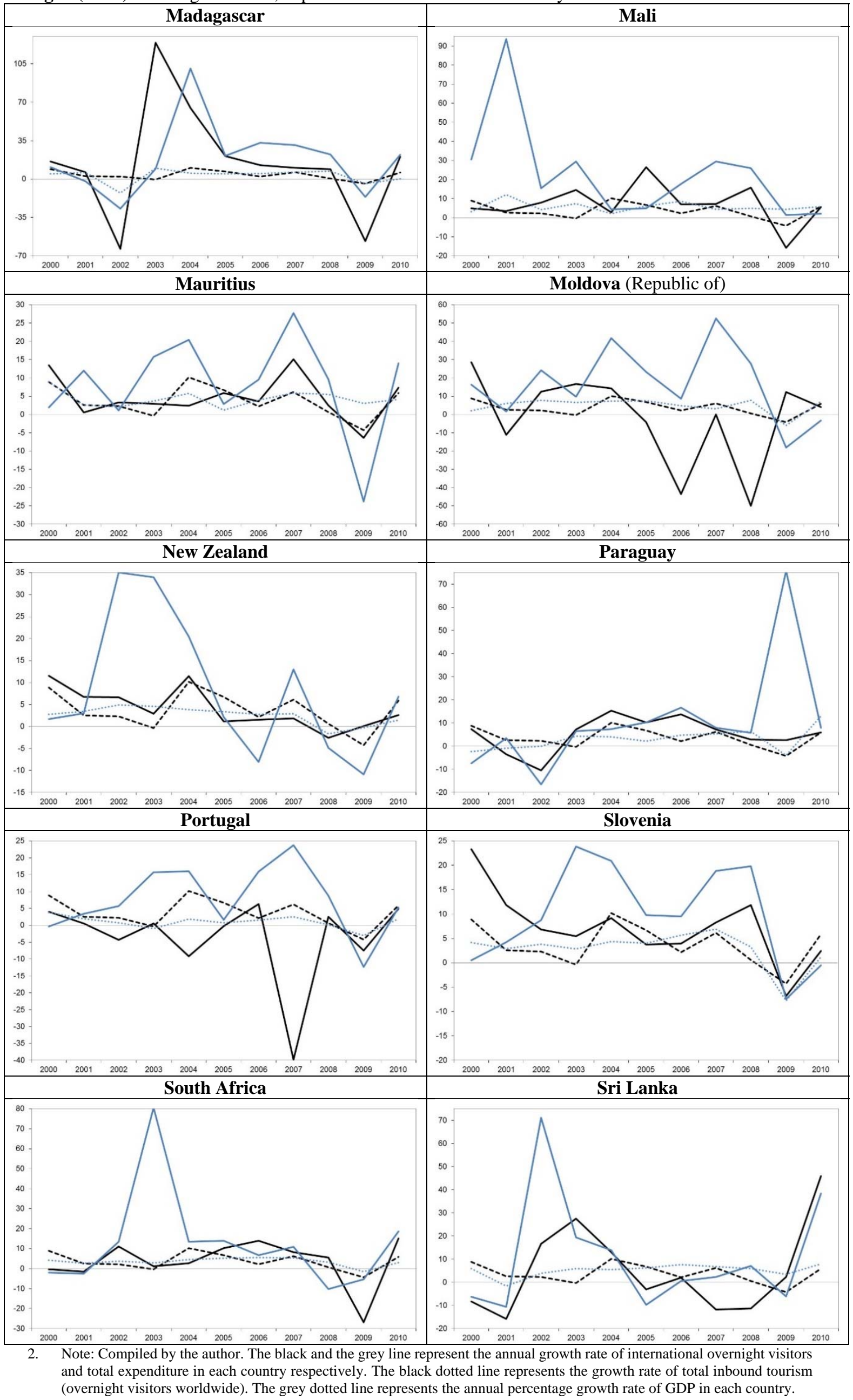


Table 3

Ranking of destinations

\begin{tabular}{|c|c|c|c|c|c|c|c|}
\hline $\begin{array}{l}\text { Expenditure } \\
\text { per tourist }\end{array}$ & $\begin{array}{l}\text { Overnight } \\
\text { visitors }\end{array}$ & $\begin{array}{l}\text { Total } \\
\text { expenditure }\end{array}$ & $\begin{array}{l}\text { Inbound } \\
\text { expenditure } \\
\text { per GDP }\end{array}$ & Rooms & Occupancy & GDP & HDI \\
\hline 1 & 2 & 3 & 4 & 5 & 6 & 7 & 8 \\
\hline Moldova & Madagascar & Mali & Madagascar & New Zealand & Croatia & Jordan & Mali \\
\hline Madagascar & Latvia & Latvia & Mali & Mali & Madagascar & Mali & Madagascar \\
\hline Mali & Botswana & Madagascar & Latvia & Botswana & Jordan & Sri Lanka & Moldova \\
\hline Portugal & Croatia & Moldova & Belize & Bulgaria & Sri Lanka & Moldova & Lithuania \\
\hline Latvia & Jordan & Jordan & Jordan & Madagascar & Moldova & Belize & Mauritius \\
\hline South Africa & Bulgaria & Bulgaria & Slovenia & Lithuania & Botswana & Latvia & Paraguay \\
\hline Ireland & Slovenia & Croatia & Portugal & Latvia & Lithuania & Bulgaria & Sri Lanka \\
\hline Belize & Mali & South Africa & Paraguay & Paraguay & Belize & Mauritius & Botswana \\
\hline Lithuania & Paraguay & Sri Lanka & Ireland & Belize & Slovenia & Botswana & Bulgaria \\
\hline Jordan & Sri Lanka & Paraguay & Croatia & Mauritius & Paraguay & South Africa & Jordan \\
\hline Sri Lanka & Mauritius & Slovenia & South Africa & Jordan & Jamaica & Cyprus & Latvia \\
\hline Paraguay & Jamaica & Belize & Mauritius & Slovenia & New Zealand & Ireland & Jamaica \\
\hline Croatia & New Zealand & Ireland & Moldova & South Africa & Cyprus & Paraguay & Croatia \\
\hline New Zealand & South Africa & New Zealand & Bulgaria & Sri Lanka & Bulgaria & Madagascar & Slovenia \\
\hline Bulgaria & Belize & Mauritius & Sri Lanka & Portugal & Mauritius & Slovenia & Cyprus \\
\hline Mauritius & Lithuania & Portugal & Jamaica & Jamaica & South Africa & Croatia & Portugal \\
\hline Slovenia & Ireland & Lithuania & New Zealand & Ireland & Mali & New Zealand & Ireland \\
\hline Cyprus & Cyprus & Botswana & Lithuania & Cyprus & Latvia & Lithuania & Belize \\
\hline Jamaica & Moldova & Jamaica & Botswana & Croatia & Ireland & Portugal & New Zealand \\
\hline Botswana & Portugal & Cyprus & Cyprus & Moldova & Portugal & Jamaica & South Africa \\
\hline
\end{tabular}

Notes: Destinations are ranked according to their annual average growth rates during 2000-2010. 
Fig. 2. Transformation plots

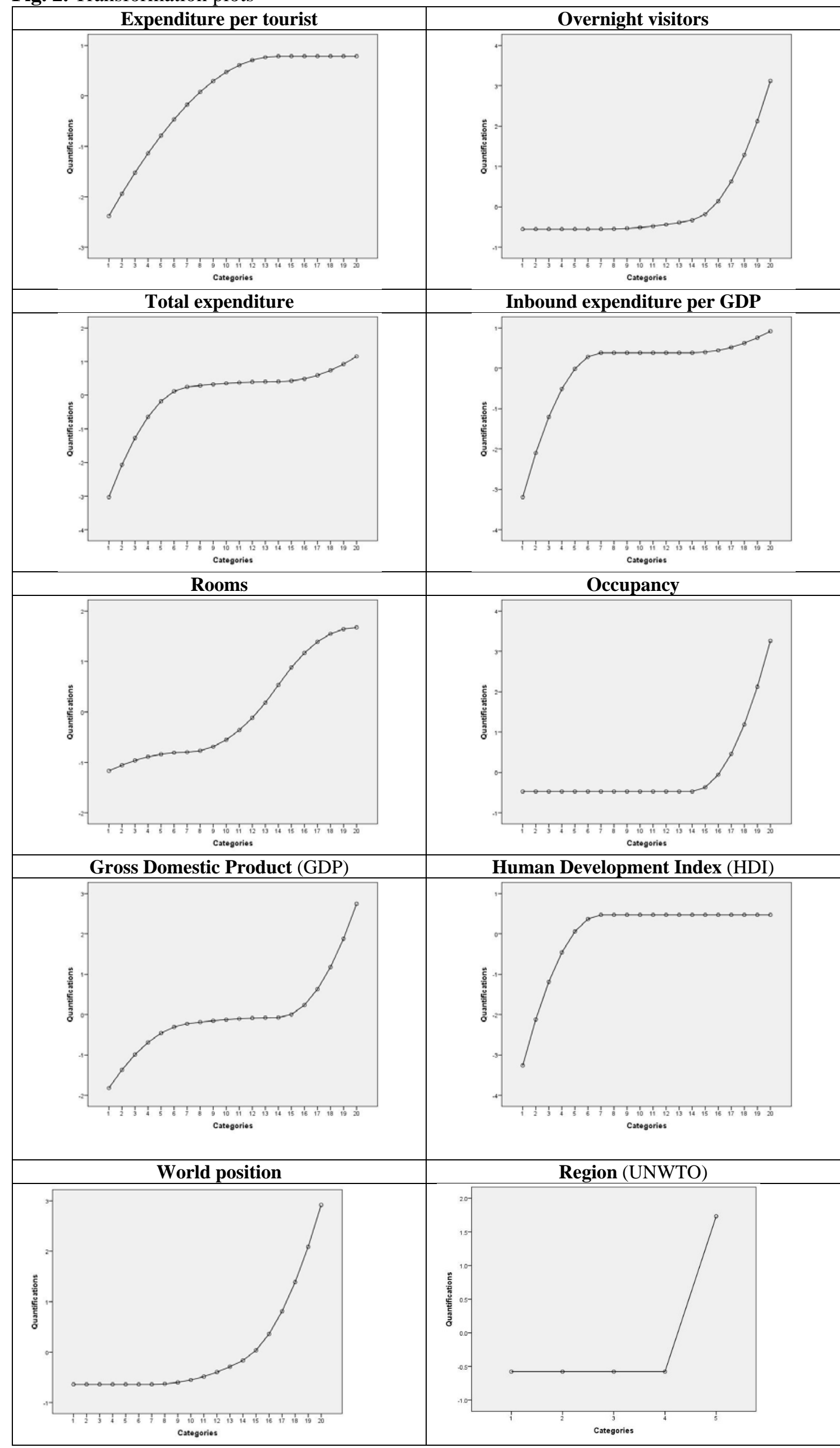


Table 4

CATPCA - Summary

\begin{tabular}{c|ccc}
\hline \multirow{2}{*}{ Dimension } & Cronbach's & \multicolumn{2}{c}{ Variance } \\
\cline { 3 - 4 } & alpha & Total (eigenvalue) & \% of variance \\
\hline $\mathbf{1}$ & 0.85 & 4.30 & 43.01 \\
$\mathbf{2}$ & 0.65 & 2.39 & 23.91 \\
Total & $0.95^{*}$ & 6.69 & 66.92 \\
\hline
\end{tabular}

Notes: *Cronbach’s alpha mean is based on the mean of the eigenvalue.

Table 5

Component loadings

\begin{tabular}{l|cc}
\hline \multirow{2}{*}{\multicolumn{1}{c|}{ Position }} & \multicolumn{2}{c}{ Dimension } \\
\cline { 2 - 3 } Expenditure per tourist & $\mathbf{1}$ & $\mathbf{2}$ \\
Overnight visitors & 0.77 & -0.58 \\
Total expenditure & 0.12 & 0.92 \\
Inbound expenditure per GDP & 0.89 & -0.02 \\
Rooms & 0.87 & 0.07 \\
Occupancy & 0.37 & 0.66 \\
GDP & -0.01 & 0.71 \\
HDI & 0.47 & 0.34 \\
World position & 0.90 & -0.09 \\
Region & -0.81 & 0.23 \\
\hline
\end{tabular}

Note: Component loadings indicate Pearson correlations between the quantified variables and the principal components (ranging between -1 and 1 ). 
Fig. 3. Screeplot

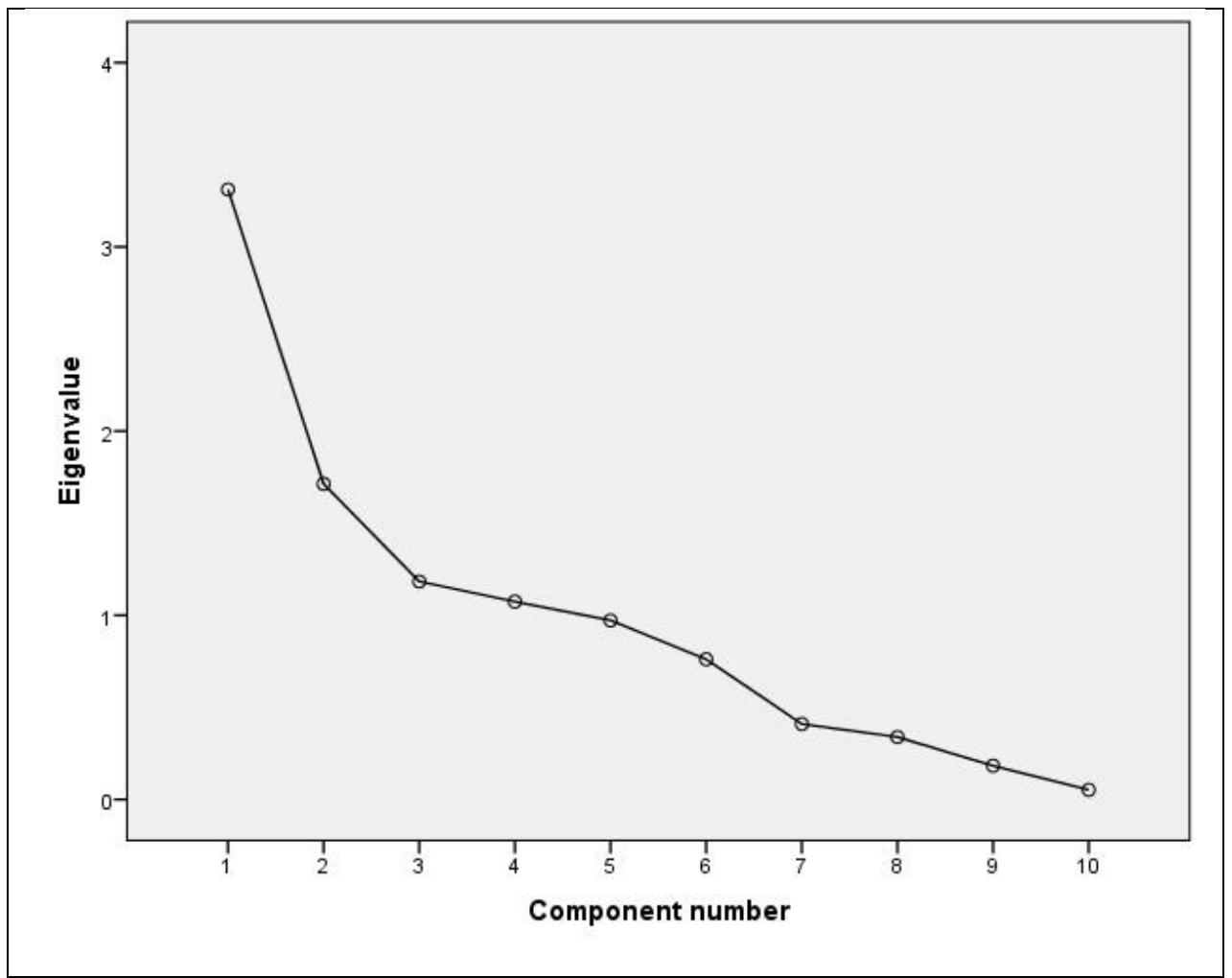

Fig. 4. Biplot

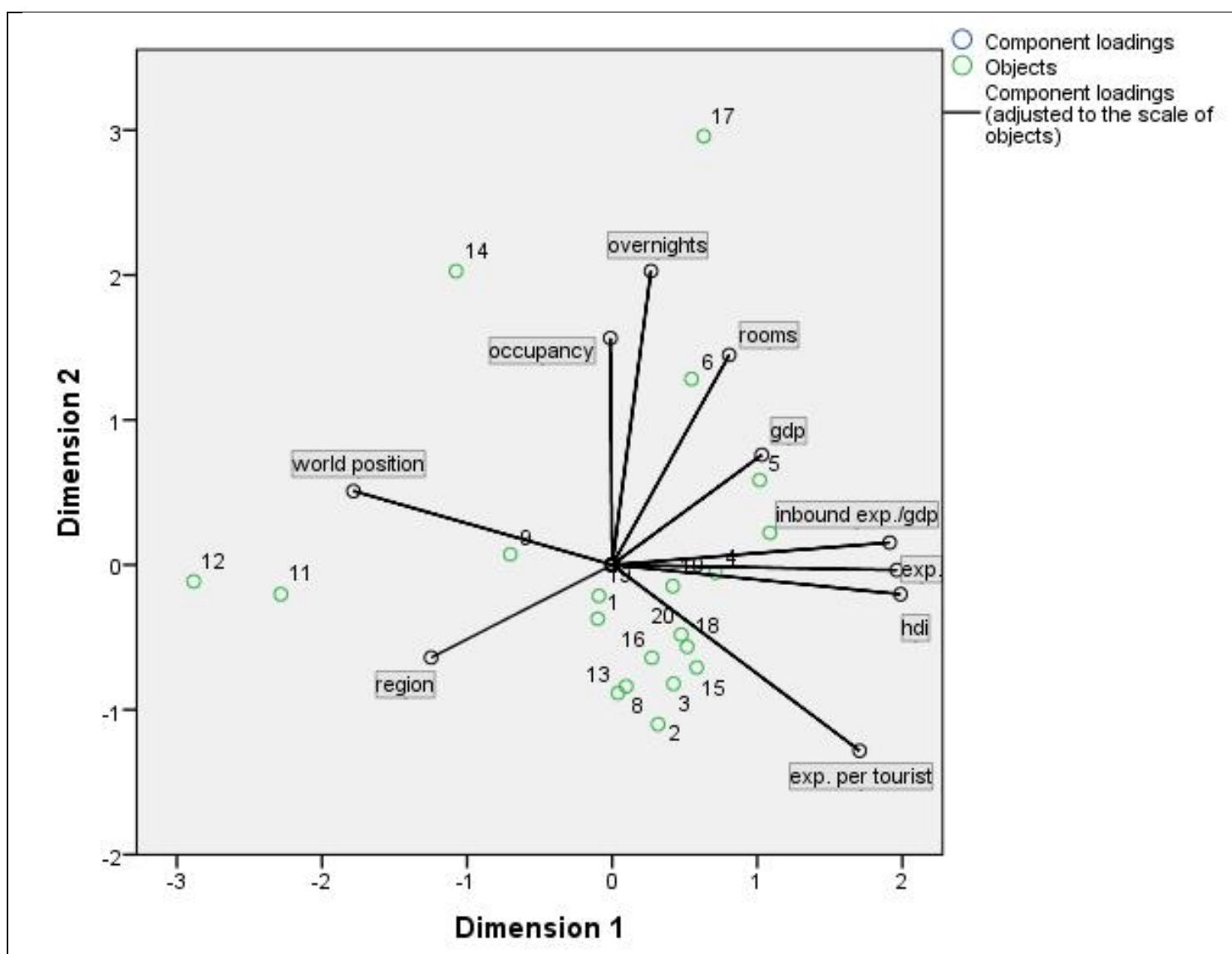


Fig. 5. Perceptual map

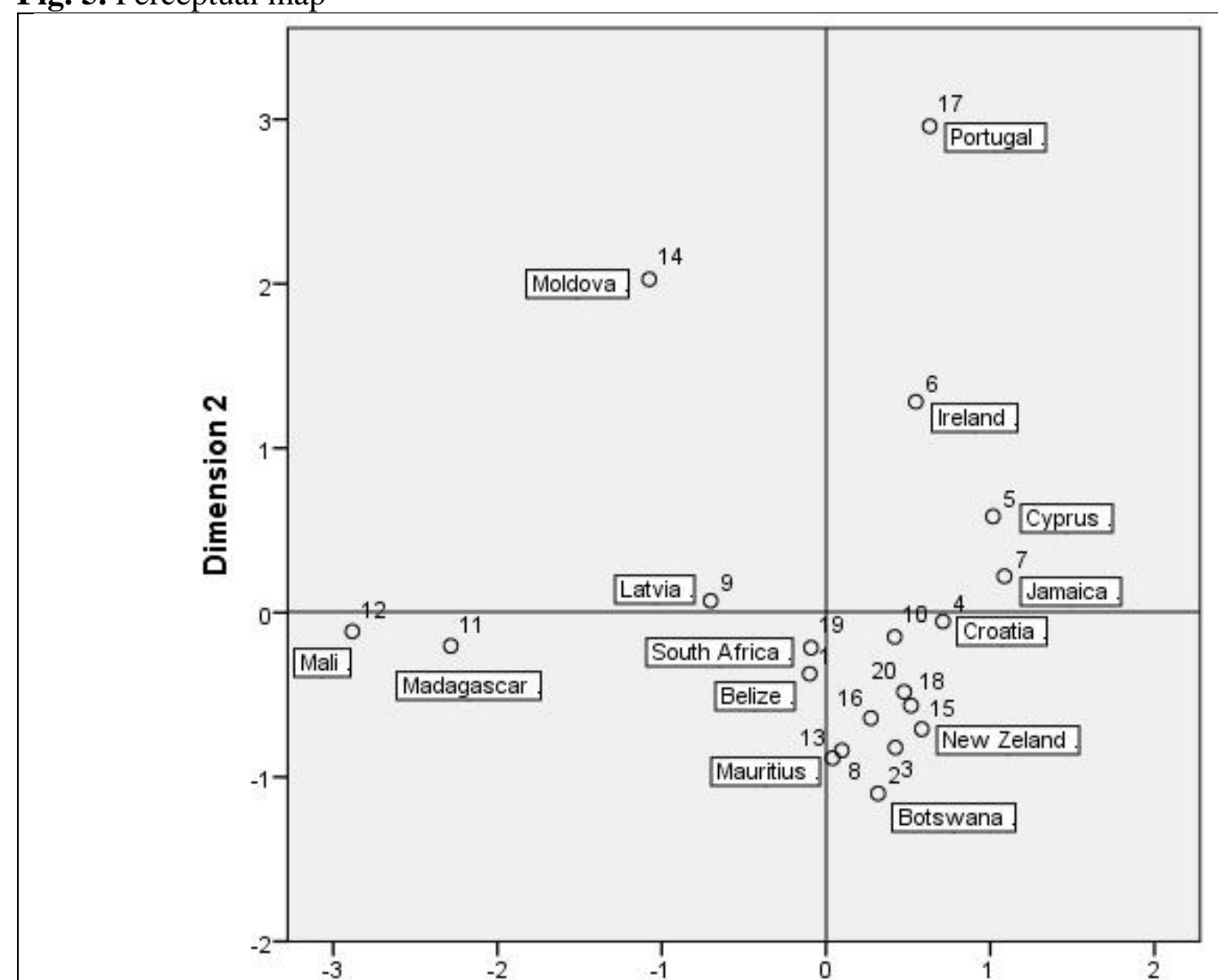

Dimension 1 